\title{
The Finnish Approach to the World Fertility Survey
}

\author{
By OLAVI RIIHINEN \\ University of Helsinki \\ Department of Social Policy \\ AIMO PULKKINEN \\ JYRKI NOPONEN and \\ MARKETTA RITAMIES
}

Population Research Institute

The fertility surveys currently underway in different parts of the world are proof that both developing countries and developed countries desire information about their fertility. Many countries with vigorous population growth do not even have basic information about fertility. Developed countries with slow population growth are usually aware of the prevailing fertility level, but on the other hand, do not know what causes have led to this situation.

In order to arrive at a unified and reliable picture of the current fertility level of the entire world the UN, together with the International Statistical Institute and the International Union for the Scientific Study of Population has undertaken the largest fertility study to date, the World Fertility Survey.

\section{Why is Finland participating in the WFS?}

In Finland, which is among the countries with slow population development, participation in the World Fertility Survey is considered timely and necessary, above all because of problems related to the development of the birthrate.

The structural change which has taken place in the Finnish society has occurred more rapidly than in most other developed countries. Society has undergone industrialization and urbanization and the population has moved to the southern parts of the country in slightly over twenty years. A graphic example of the swiftness of the transition is the reduction in the proportion of the economically active agrarian population. It has dropped from $46 \%$ to $20 \%$ between the years 1950 and 1970 .

The change in the society is also visible in the birthrate figures. In Finland in the mid-1950s there were still 21 children born per 1000 inhabitants. In 1972 the figure was only 12 births. After this the birthrate has risen slightly and was 14 births per 1000 inhabitants in 1976. Finland's birthrate is one of the 
lowest in the world, but the age structure is still relatively quite favorable, however. The number of women of childbearing age continues to grow.

Finland's greatest problems have been an unstable birthrate and unstable population development, which swing from one direction to another. The large fluctuations occurring annually in the number of births cause problems with far-reaching effects. The large age groups born after the war in 1946-50 - in 194728 children per 1000 inhabitants were born - afford a good example of this. In all stages of their life these age groups have caused and evidently will continue to cause difficulties. These problems will most likely be at their greatest when these age groups reach retirement age; the current small age groups will then have to look after abnormally large passive age groups.

The greatest significance of the World Fertility Survey for Finland is that Finland hopes it will shed light on why the size of the Finnish family has diminished so strongly, why there is an average of only 1.6 children in every family. If this survey helps to discover what factors regulate having children, it might be possible to avoid great swings in the birthrate in time and it may be possible to direct the development of the population in the desired direction by means of various societal policy measures.

\section{The frame of reference of the Finnish survey: a need-theory approach}

Fertility studies can probably be considered a difficult area of social research from the point of view of theory. Indeed, many fertility studies have been of a pure statistical nature without a theoretical basis. This basic situation was recognized when the World Fertility Survey began in Finland. The Finnish research team considered it more to the purpose, however, to attempt a relatively daring theoretical approach rather than to be satisfied with a study without theory.

From among the many approaches it considered, the Finnish research team chose need theory as the core of its theoretical approach. As far as we know this kind of theory has not been applied previously to fertility studies. The choice made in Finland was influenced mainly by a historical examination: the development of fertility seemed to support the supposition that the level of basic human need satisfaction is related to the number of children in the family at the time.

In choosing a need-theory approach many different options are available: researchers have presented numerous need theories and their variations. A presentation of different theories is not possible here. However, mention should perhaps be made of a certain basis for classifying need theories, significant in this study, namely whether or not the theory contains an explicit assumption of a hierarchy of needs. Here a hierarchy of needs means a dynamic situation, where the increasing satisfaction of a certain level of needs is assumed to lead to increased pressure toward the satisfaction of higher-order needs. The best- 
known hierarchical need theory is the five- or six-level system developed originally in the 1940 s by Maslow. An example of a need theory which does not assume a hierarchical structure is the system developed by Etzioni (1968).

Even if the supposition of hierarchy is not explicitly mentioned in the theory, it seems to be included implicitly in every need theory. It is mainly a question of the significance of hierarchy as a characteristic of the need system. The principle of hierarchy in itself is most likely related to an assumption about the development of the individual and of social entities. When the individual or social entity has reached a certain developmental level, new matters take on importance and are considered worth striving for. In hierarchical need theories it is assumed that this development follows a more or less regular course, as if it would advance through certain phases. One need not emphasize that in development of this sort all specified phases are simplifications.

In the Finnish fertility survey Maslow's hierarchical theory was chosen as a basis. This theory, as it is usually presented, assumes five need levels: physiological needs, safety needs, relatedness, self-esteem and the highest category, selfactualization needs. Maslow's theory has often been interpreted in a way that assumes that the author meant that the hierarchy levels were very distinctly separate from each other. This interpretation differs from Maslow's own view, however, according to which the boundaries between the hierarchy levels are not clear-cut and individual deviations from the general hierarchy exist. Maslow's theory has been redefined, however, and in a very justified manner. One such attempt at clarification, which seems successful, is Alderfer's (1959) ERG-theory, where the needs have been concentrated into three main categories: existence needs (E), relatedness needs (R) and growth needs (G). Alderfer has also taken into account frustration situations, where the individual does not succeed in satisfying his needs and is forced to return to an earlier level.

When examining the development of fertility over a long period of time, one notices that during the age of industrialism fertility has continually declined, with a few minor exceptions. The transition in the industrial structure is seen as the main cause of this developmental trend. When examined according to need theory the function of children in an agrarian society was quite different from their function in an industrialized and urbanized society.

The general need satisfaction level of people in an agrarian society was decisively lower than in an industrial society. To a great extent people in an agrarian society continued to struggle with the problem of satisfying physiological needs and safety needs. Because of the structure of the agrarian society, the primary group - the family, relatives, the village - was a central safety factor. At the same time the size and continuity of the social entity were essential conditions determining the continuity of safety. In order to safeguard their old age people had to have a sufficient number of children: children functioned as social security for their parents.

As society became more industrialized the satisfaction of safety needs had to be rearranged. When mobility increased and a transition to a trade-based 
economy occurred, the ties between parents and children quickly weakened. Children were no longer able to guarantee the livelihood of their parents in their old age. Society created the social security system and took over a large share of the tasks formerly belonging to the family.

In industrialized societies it seems that physiological and safety needs are generally quite well satisfied. People no longer feel it necessary to have a large family in order to assure the satisfaction of their own safety needs. In the light of Maslow's theory one can assume that the problems of industrialized society lie in the satisfaction of higher-order needs: how to feel that one is loved and belongs to some social entity, how to gain esteem in an ever more massive and mechanistic society, how to find self-actualization in one's work, which usually takes place to a very great extent on someone else's terms.

Children most likely mean even more to their parents as objects of love and attachment in an industrialized society than they do in an agrarian society. Social detachedness and even loneliness are characteristic of an urbanized society. In a situation like this children may have a new function as the object of their parents' love and social contacts. But it is probable that relatedness needs and love needs do not require a large number of children; the satisfaction of affection and affiliation needs does not necessitate a swarm of children, which was practical as a source of labor and an assurance of continuity in an agrarian society. Besides, an urban environment sets new economic limits on the number of children, limits related to a rise in the level of aspiration.

As the standard of living rises the satisfaction also of one's highest needs has become more and more important. At this time people seek opportunities in a competitive society to achieve esteem, which often means long-term education and accumulation of professional skill. It is also probable that the striving for self-actualization is often emphasized in a society of a high standard of living. When, for example, the level of education is high, people actively seek out means with which to realize life goals which have gradually taken shape. The more educated people are, the more they have invested mentally in certain life goals, the more reluctant they are to forego these goals. Therefore it is presumable that having children comes into conflict in society with the satisfaction of certain basic needs.

At this point it is not possible to specify in detail the assumptions included in the Finnish survey concerning conflicts between various needs or to specify how these conflicts are reflected in fertility behavior.

It can be assumed, however, that differences corresponding to different developmental phases of society exist in the Finnish urban and rural society. Correspondingly, the fertility behavior of families living at different levels of need satisfaction are likely to vary from each other. One still undetermined fact is how large a portion of the population lives at the bottom limit of basic need satisfaction, and how this is reflected in fertility behavior in various subcultures. Partially conflicting assumptions on this matter exist. 


\section{The suitability of the international interview form in Finland}

The interview form drawn up at the central office of the World Fertility Survey in London is the core of the national studies in each country.

From Finland's standpoint this carefully compiled and tested interview form does not fulfill all demands, however. Some basic information on fertility levels and differences already exists in Finland (Ritamies-Visuri, 1975; Sievers-Koskelainen-Leppo, 1974), but studies attempting to clarify motives determining family size are lacking almost completely. Therefore, the main emphasis of this study had to be focused on clarifying the causes affecting the birthrate and this area had to be accentuated in the international questionnaire with additional questions.

The basis of the international fertility study was also unsatisfactory in that it set forth without a theoretical framework, and therefore the study's approach is mainly statistical. However, an overall analysis of fertility behavior necessitates a framework with which to see that the questions form a logical explorative of the problem. Only thus can information obtained in the study on marriage, number of children, probability of becoming pregnant and knowledge of contraceptives, among other matters, be linked with fertility behavior.

The international questionnaire also does not contain questions on many factors prevailing in various sectors of society and affecting the number of children, factors which experts in different fields and the ruling bodies can use in planning and developing measures with which to attain balanced population development.

Correspondence with the core interview form

The international core questionary, with some technical changes was included in the Finnish interview form, of which it formed about one half. The essential part of the Finnish form consisted of questions aiming at the formulation of explanatory variables and taking into consideration conditions in Finland.

Similarly an attempt has been made to guarantee that the questions in the interview form can be compared with survey data gathered in 1971 on the fertility behavior of Finns, data which was published in 1975 under the title »Finnish Family Size - Accidental or Planned", which also formed Finland's share in the fertility survey comparing 12 European countries, called $»$ Fertility and Family Planning in Europe Around 1970: A Comparative Study of National Surveys".

The questionnaire also contains most of a module compiled by the ECE secretariat called »Family size preferences and motivations». This makes it possible 
for Finland to participate also in another study comparing fertility in European countries, the ECE Comparative Study 1975.

The international questionnaire consists of eight parts: the respondent's background, pregnancy history, knowledge of contraceptives, previous family planning, marriage history, current birth control, work history and husband's background. In the Finnish questionnaire this division has remained basically the same. The section on marriage history was left out, however, because the Finnish survey only included women in their first marriage. Questions on previous marriages were therefore unnecessary.

To same extent questions from the core questionnaire were transferred to other parts of the form and similarly, other questions were combined. In this way we facilitated the work done by the interviewers. A simplification was made in the pregnancy history inquiry: only the total number of short-term pregnancies was asked. They were not included in the pregnancy table, because we felt it was too delicate a matter to inquire about in detail and we also felt it was too difficult for the interviewee to remember about them.

The target areas of additional questions in the Finnish survey

The simplification and shortening of the questionnaire made it possible to add questions which were necessary in examing our own national needs and viewpoints. These questions were not drawn up on the basis of separate international WFS-modules instead they concerned questions of special interest to Finns. The additional questions concerned housing conditions, standard of living, consumer behavior, the employment of women, interpersonal relationships, children's day care and the social climate of the childhood home, among other matters. These questions were placed in those parts of the international interview form which best corresponded in content.

In compiling additional questions we were faced with a dual problem. Even though the interview form had been shortened, it was still so lengthy that we were not able to achieve with the additional questions the coverage required in a behavioral study. On the other hand, we were moving in such a problematic area of theory that the validity problem of the data obtained with questionnaire and interview methods was very difficult. Finally we decided to include a series of questions in the interview form covering sections on the most essential concrete living conditions and a series on the satisfaction level of needs, a much more problematic matter.

It is relatively easy to inquire about the number of children in the family and even to ask about plans to have children. Both answers are based on information held by the respondent and on her personal views. On the other hand, it is much more difficult to discover why some families have two children, some have one and some have none. The respondent does not know or is not aware of causal relationships, much less of various aspects pertaining to inter- 
relations and their emphasis. This concerns total human behavior, where the determination of family size plays only a minor role as an aim.

When talking about the family, one must also talk about housing. It is not so much a question of housing as a dwelling unit, as it is a question of the range and variety of the possibilities it offers. Housing conditions in Finland have improved decisively in the last two decades, but nevertheless the housing question is still a problem for many citizens. Therefore we wanted to add questions concerning housing to the interview form. There were a total of 18 questions on housing. We felt it necessary to obtain information not only on the family's present dwelling, its size, the type of building and tenure status, but also about the couple's first dwelling after marriage as well as possible plans about changing their current form of housing. All of these were seen as related in one way or another to having children and to future family planning, but the research team was mainly interested in discovering the ultimate role of the dwelling in family planning and in what population groups this role would be most evident and actually seem to affect fertility behavior.

A relationship is also seen between having children and the general economic situation of the family. The continuous drift away from an agrarian society has transformed the position of children, who have mainly become consumers as far as the family is concerned when formerly they were production units and individuals who would carry on the work of the family. Despite society's support many feel that having children means narrowing down their own opportunities for consumption and at least momentarily lowering their current standard of living, especially when the family has set goals for itself which require economic outlay. Changes are expected in how the family's income is used; whether they are imagined or actually significant cannot usually be answered until after the fact.

The conflict is more pronounced if the decision to have children also means that the wife may be prevented from going to work or may find it generally more difficult to do so. In Finland $2 / 3$ of all wives of childbearing age are employed outside the home, and therefore the answer to this problem concerns most of them. When, in addition, we remember that an average of one out of two matriculated students is female and that the proportion of women in the group with an academic degree is almost as high, 4/10, gaining employment and staying in the working world can also be motivated by the desire to make use of one's own personal opportunities and by the feeling that the work is of value.

According to the Finnish research team the decision to have children should not be examined separately, instead it should be seen as a part of need behavior. Thus the dual role of the wife as a jobholder and as a homemaker can quite often become problematic. A total of thirty questions concerning these matters were added to the questionnaire.

In addition to aspects relating to working life and to the daily economic management of the family household attention was focused on the ability and opportunities of the spouses to make friends and on their desire to participate 
in the activities of various associations and clubs. Contacts with the world outside the home are most likely reflected in the relations between family members, if not otherwise, at least in the amount of time available for being together, but being already accustomed to using opportunities for participation outside the home may also extend an influence on future family planning.

Attention was also focused on how child day care was arranged. Several questions concerned day care, what arrangements are currently made for the day care of children of different ages and what does the respondent consider the best form of day care. It can be assumed that different arrangements are linked, via personal opinion and experience, to whether the wife is employed or is a housewife and can thus be a partial influence in determining not only the present number of children in the family but also future family planning.

In addition to questions concerning material factors in the standard of living, there were others on the social climate of the family and its psychological effects. Relations between family members, whether spouses confided in each other, and the meaning children had for the parents were all given attention.

And as behavior models are often learned though personal experiences, the childhood home was not forgotten. In addition to social background and current class identification, the research team was interested in the climate of the childhood home, the growth environment and experiences of each respondent in her childhood and teenage years.

\section{The actual fertility survey interviews}

Drawing the study sample

According to the recommendation of the World Fertility Survey head office in London, the study sample of each country participating in the survey should represent as well as possible the ever-married, childbearing-aged (15-49-yearold) female population of the country. If it were not possible to use the entire female population as the base population of the study, an alternate recommendation was all currently-married women. The Finnish research team decided that the basic population of the study would be 18-44-year-old women currently in their first marriage. This was mainly due to the fact that the proportion of the female population who were married and under 18 is very small in Finland and giving birth to children under the age of 18 or over the age of 44 is extremely rare. Limiting the population only to women currently in their first marriage came about because the number of women who were divorced, widowed or in their second or later marriage would have been too small for effective analysis. Then again choosing and analyzing a divided sample was considered too difficult, because the questionnaire would correspondingly have had to be expanded too much.

The size of the sample was fixed at 6200 women and it was decided to draw 
it at random among the population of the entire country, not including the sparse population of the Ahvenanmaa Islands. This limit was set mainly because of interviewing difficulties. A two-stage sample was abandoned, because it was felt that the size of the sample, its drawing ratio and the homogeniety of the Finnish population would guarantee that the sample would be representative in the relevant criteria. The criteria considered most essential in Finland were the age structure and regional distribution of the population and the most important socio-economic variables. Even though the representativeness of the age structure is not as essential from Finland's standpoint as it is in developing countries, the sample was drawn, for reasons of sample technique, equidistantly according to age among the basic population of 571840 women, which resulted in a final sample ratio of 92 . The Finnish sample was drawn so that the basic population was formed by the women defined above, and not by families. It was felt that this method would be the best way to achieve a representative sample, at the same time it facilitated the interviews and the analysis of the sample loss. The sample was drawn on January 30, 1977 from the central population register at the National Statistical Center.

Part of the 6200 women drawn in the sample did not belong to the basic population of the study because their marital status had changed or they were living abroad. For this reason 161 women were left out of the study. While the checking of the fieldwork phase of the survey is still going on, the sample representing the basic population is 6001 women at this writing, 5435 of whom were interviewed and 566 of whom were not, mainly because they refused or could not be located.

\section{Interview organization}

The interviewers in the study were public health nurses, who already had interview experience from previous surveys made in Finland. Among other surveys was the previously mentioned fertility study made 1971, where public health nurses also did the interviews. They were considered the best interviews possible because the questionnaire contains certain very intimate questions related to having children and the use of contraceptives.

Before the interview phase of the study began all 214 of Finland's health centers were contacted, because their approval was the final factor deciding whether the public health nurses could be used as interviewers. Despite a very pressing work situation a favorable agreement was reached and only 14 interviews were left undone because interviewers were not available.

The interviewers were trained in a total of 17 training sessions held by the members of the research team. A total of 400 interviewers and contact persons, who gave further training, participated in these sessions. The interviews were begun on March 16, 1977 and the fieldwork phase can be said to have ended on 
June 20, when $98 \%$ of the interviews had been completed. It is almost impossible to give an exact estimate of the final number of interviewers, because there were so many different ways in which the health centers arranged the interviews in their area. In Helsinki four interviewers completed 465 interviews, in Turku about 100 interviewers completed a total of 183 interviews. An estimated 1300 interviewers participated in the completion of the fieldwork phase of the study.

Size, distribution and causes of sample loss

The percentage of loss in the entire country was 9.4 , which corresponded to what was expected. Compared to the afore-mentioned 1971 study of evermarried women, the loss has risen about three percentage points and the increase has occurred mainly among the refusals. One can only venture a guess about what has caused this increase, but the recent public discussion on the safeguarding of privacy and on keeping information confidential, the tense economic situation prevailing at the time of the interviews, including layoffs and forced leaves, and the bus strike which lasted one month just at the time of the interviews cannot have avoided having an effect the size of the loss. It is obvious, of course, that the work situation of the interviewers and the nature of the interview task as "extra work" may have affected the loss, which was evident in the very uneven distribution of the loss in different communities.

Because the computer analysis of the research data is still ahead, the examination of the representativeness of the loss and of the interviewed sample has to remain quite superficial at this phase. The only information available about the basic population of the study that can be used in determining the representativeness of the sample is the age structure and distribution of the population in different provinces on December 31, 1974, which was over two years age. The examination of the loss will also be made according to the type and size of community where the interviewee lives (Table 1).

$\mathrm{Table}$ 1. Percentage of loss examined according to size of city $^{1}$, type of community and age.

$\begin{array}{lrrrrrr}\text { Age } & 18-24 & 25-29 & 30-34 & 35-39 & 40-44 & \text { Total } \\ \text { Helsinki area } & 11 & 10 & 11 & 15 & 18 & 13 \\ \text { Other large cities } & 10 & 11 & 8 & 13 & 14 & 11 \\ \text { Small cities } & 10 & 13 & 8 & 10 & 11 & 10 \\ \text { Rural communities } & 7 & 6 & 5 & 6 & 8 & 6 \\ \text { Finland, total } & 9 & 9 & 7 & 10 & 11 & 9\end{array}$

1 Large cities are those whose registered population totaled over 50000 inhabitants on January 1, 1975. 
The distribution of the loss corresponded to normal results. Refusals and unsuccessful contact of persons were most common in the oldest age groups in the large cities. The interviews were most successful in the rural areas and generally in the middle age groups, who can be assumed to be most interested in the object of the study. As was already mentioned earlier, there was quite a large local variation in the loss. Among the 13 largest cities, the loss remained under $6 \%$ in three cities and exceeded $15 \%$ in three others. There were even a few small cities where the loss approached 40 percent.

The distribution of the loss in the different provinces was also relatively uneven, and no clear-cut regularity could be evidenced (Figure 1). A larger than average loss appeared in both the densely populated southern parts of the country and in the sparsely populated northern and eastern parts. The high loss percentage on the western coast (Province of Vaasa) was caused partly by the 14 interviews which were not made because of a lack of interviewers. Correspondingly, there was a slight loss in both the urban and industrialized southern parts of Finland and in the agricultural-based central and northern parts of Finland. The large differences between the various provinces can be explained in part by the varying loss percentages in the largest cities.
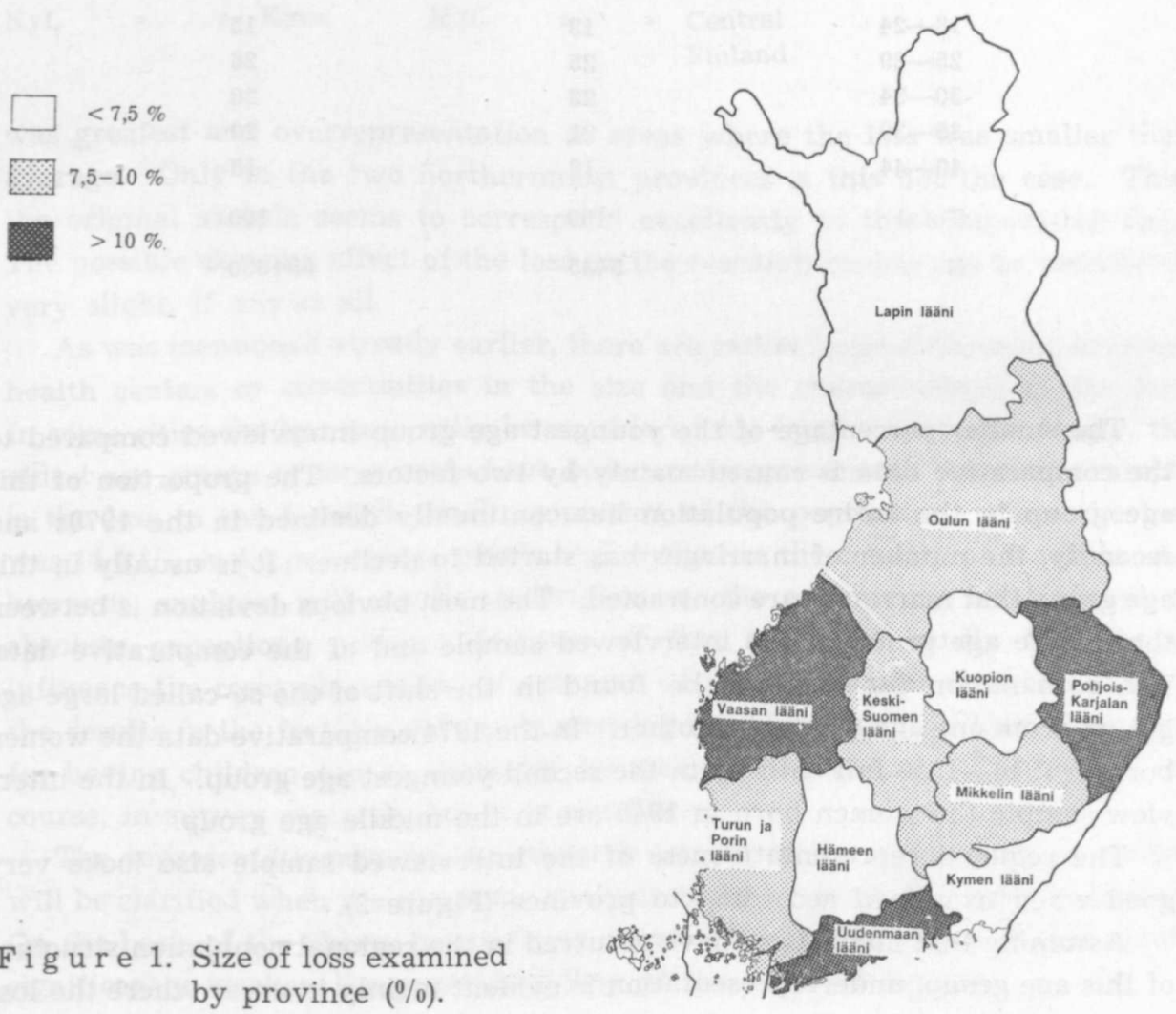

Fig u r e 1. Size of loss examined by province $(\%)$. 
The representativeness of the interviewed sample

The determination of the representativeness of the sample would require comparative information about the basic population used in the study. At this stage the only information available is preliminary data from the population change statistics of 1974, and this information is limited to the age structure, examined by province, of currently-married women living in Finland on December 31,1974 . Thus, the comparative data also includes women in their second or later marriage, who are, however, relatively few in number, and who are concentrated mainly in the oldest age groups of the comparative data.

The correspondence between the age structure in the interviewed sample and in the comparative data is excellent (Table 2).

$\mathrm{T}$ a ble 2. Interviewed sample and currently-married female population on December 31,1974 corresponding in age, examined by age groups $(\%)$.

\section{Interviewed sample}

$\begin{array}{lr}18-24 & 13 \\ 25-29 & 25 \\ 30-34 & 23 \\ 35-39 & 21 \\ 40-44 & 18 \\ \text { Total } & 100 \\ \text { N } & 5435\end{array}$

Currently-married 18-44-year-old female population in 1974

15

26

20

20

18

100

594650

The smaller percentage of the youngest age group interviewed compared to the comparative data is caused mainly by two factors. The proportion of this age group in the entire population has continually declined in the $1970 \mathrm{~s}$ and secondly, the number of marriages has started to decline. It is usually in this age group that marriages are contracted. The most obvious deviation is between the middle age group of the interviewed sample and of the comparative data. The explanation for this can be found in the shift of the so-called large age groups from one age group to another. In the 1974 comparative data the women born in 1946 - 1950 fall entirely in the second youngest age group. In the interview sample the women born in 1946 are in the middle age group.

The regional representativeness of the interviewed sample also looks very good when examined according to province (Figure 2).

Assuming that no changes have occurred in the regional population structure of this age group, underrepresentation is evident mainly in areas where the loss 
Figure 2. The distribution of the interviewed sample and of the currentlymarried women of corresponding age on December 31, 1974 according to province $(\%)$.

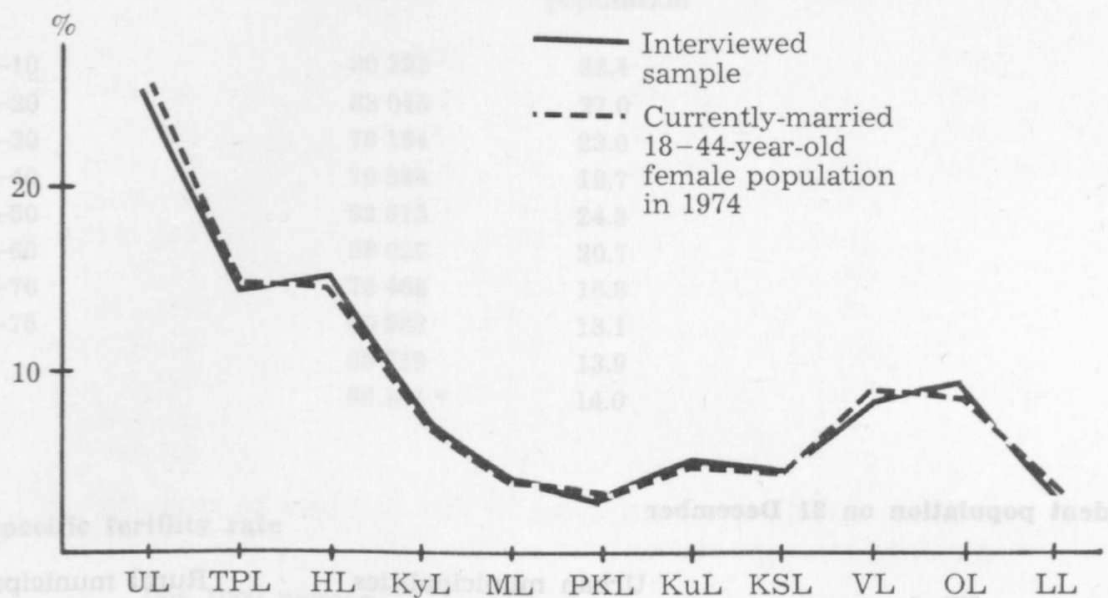

UL Province of Uusimaa ML Province of Mikkeli

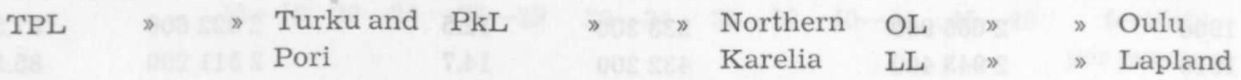

$\begin{array}{lllll}\mathrm{HL} & \text { \# } & \text { Häme } & \mathrm{KuL} \text { Province of } & \text { Kuopio } \\ \mathrm{KyL} & \text { Kymi } & \mathrm{KSL} & \text { Central } \\ & & & & \end{array}$

was greatest and overrepresentation in areas where the loss was smaller than average. Only in the two northernmost provinces is this not the case. Thus the original sample seems to correspond excellently to the comparative data. The possible skewing effect of the loss on the research results can be considered very slight, if any at all.

As was mentioned already earlier, there are rather large differences between health centers or communities in the size and the characteristics of the loss. In some cities the loss can really be considered too large. Correspondingly, the oldest age groups in some areas have been underrepresented. Another example is the loss in the Swedish-speaking portion of the population, where the loss was $14.0 \%$, or 4.6 percentage points higher than in the country as a whole. As, however, analyses will not be undertaken on the community level except as absolute exceptions perhaps, features of this sort will hardly be able to influence the research results. If a danger of this sort is seen to exist, at least the results in the fertility survey concerning the number of children and plans for having children can be corrected by means of weighting. This is rare, of course, in survey research, but it is possible.

The representativeness of the research sample in the light of other criteria will be clarified when the computer analysis of the research data gets underway. On the basis of the above, however, no skewedness can be expected that would significantly weaken the generalizability of the research results. 